\title{
Genome sequencing and transcriptome analysis of Trichoderma reesei QM9978 strain reveals a distal chromosome translocation to be responsible for loss of vib1 expression and loss of cellulase induction
}

Christa Ivanova ${ }^{1,6^{*}} \mathbb{D}$, Jonas Ramoni², Thiziri Aouam¹, Alexa Frischmann², Bernhard Seiboth², Scott E. Baker ${ }^{3}$, Stéphane Le $\mathrm{Crom}^{4}$, Sophie Lemoine ${ }^{5}$, Antoine Margeot ${ }^{1}$ and Frédérique Bidard ${ }^{1 *}$

\begin{abstract}
Background: The hydrolysis of biomass to simple sugars used for the production of biofuels in biorefineries requires the action of cellulolytic enzyme mixtures. During the last 50 years, the ascomycete Trichoderma reesei, the main source of industrial cellulase and hemicellulase cocktails, has been subjected to several rounds of classical mutagenesis with the aim to obtain higher production levels. During these random genetic events, strains unable to produce cellulases were generated. Here, whole genome sequencing and transcriptomic analyses of the cellulase-negative strain QM9978 were used for the identification of mutations underlying this cellulase-negative phenotype.

Results: Sequence comparison of the cellulase-negative strain QM9978 to the reference strain QM6a identified a total of 43 mutations, of which 33 were located either close to or in coding regions. From those, we identified 23 single-nucleotide variants, nine InDels, and one translocation. The translocation occurred between chromosomes $V$ and VII, is located upstream of the putative transcription factor vib1, and abolishes its expression in QM9978 as detected during the transcriptomic analyses. Ectopic expression of vib 1 under the control of its native promoter as well as overexpression of vib1 under the control of a strong constitutive promoter restored cellulase expression in QM9978, thus confirming that the translocation event is the reason for the cellulase-negative phenotype. Gene deletion of vib 1 in the moderate producer strain QM9414 and in the high producer strain Rut-C30 reduced cellulase expression in both cases. Overexpression of vib1 in QM9414 and Rut-C30 had no effect on cellulase production, most likely because vib1 is already expressed at an optimal level under normal conditions.
\end{abstract}

Conclusion: We were able to establish a link between a chromosomal translocation in QM9978 and the cellulasenegative phenotype of the strain. We identified the transcription factor vib1 as a key regulator of cellulases in T. reesei whose expression is absent in QM9978. We propose that in T. reesei, as in Neurospora crassa, vib1 is involved in cellulase induction, although the exact mechanism remains to be elucidated. The data presented here show an example of a combined genome sequencing and transcriptomic approach to explain a specific trait, in this case the QM9978 cellulase-negative phenotype, and how it helps to better understand the mechanisms during cellulase gene regulation. When focusing on mutations on the single base-pair level, changes on the chromosome level can be easily

\footnotetext{
*Correspondence: christa.ivanova@pasteur.fr;

frederique.bidard-michelot@ifpen.fr

1 IFP Energies Nouvelles, 1-4 Avenue de Bois-Préau,

92852 Rueil-Malmaison, France

Full list of author information is available at the end of the article
} 
overlooked and through this work we provide an example that stresses the importance of the big picture of the genomic landscape during analysis of sequencing data.

Keywords: Trichoderma reesei, Genome analysis, Transcriptome, vib1, Cellulase production, Promoter, Translocation

\section{Background}

In order to bypass the current dependence on fossil resources and to reduce carbon dioxide emissions, cellulosic and hemicellulosic polymers are considered as environmentally clean and renewable energy sources and are used for the production of bioethanol and platform chemicals. Lignocellulosic material as found in agricultural crop residues, grasses, and wood must undergo physical and chemical pre-treatment before fermentable sugars can be released by the action of cellulosic enzymes. The production costs of those enzyme cocktails are still very high and present a limiting factor in the production of second-generation biofuels [1].

Trichoderma reesei, a filamentous fungus naturally found growing on decaying wood, is well known for its high capacity to secrete large amounts of cellulolytic enzymes and some strains are commonly used as industrial protein production hosts $[2,3]$. All $T$. reesei mutants which are currently used for industrial enzyme production or academic research originate from a single wildtype strain (QM6a) isolated on the Solomon Islands during the second world war due to its capability to degrade the cotton fabric of tents of the US army troops stationed there [4]. The strain was part of the US Army Quartermaster (QM) culture collection, and its cellulase system has been characterized over several decades [5]. During the first oil crisis in the 1970s, improved T. reesei strains were chosen for industrial enzyme production [5-7].

Since then, different mutagenesis programs have produced several strain lineages of $T$. reesei, some with higher enzyme production capabilities and some with lower or absent cellulase production [8] (Fig. 1). Most notably, the strain lineage developed at the Rutgers University in the 1970s produced strain Rut-C30, with the highest cellulase production levels available for academic research [7]. Strains QM9414 and QM9978 are both a product of mutagenesis programs at the US Army Natick laboratories. Whereas QM9414 serves as a common reference strain due to its moderately improved cellulase production, QM9978, QM9979, and QM9136 have cellulase-negative phenotypes providing an opportunity for understanding the mechanisms underlying cellulase regulation [9]. Indeed, the genetic causes leading to cellulase overproduction remain relatively uncharacterized. Only a few examples exist where a specific genetic change could be linked to an improved or decreased cellulase production $[8,10-16]$. Whole genome sequence analysis of several strains has contributed to the understanding of the involved mechanisms [13, 14, 16-18] (Fig. 1).

In this work, we chose the strain QM9978 as a model to understand cellulase production as it is a cellulase-negative strain and the cause for it was yet unknown.

Earlier studies on strain QM9978 suggested that there is a defect in the cellulase induction process but not in the basal expression of cellulase genes [9]. The uptake of cellobiose and sophorose is not affected suggesting that its cellulase-negative phenotype is most likely a result of a defective component specifically involved in the regulation of cellulase expression rather than during induction [19]. Another study using gene expression analysis of QM9414 and QM9978 on sophorose performed by the rapid subtraction hybridization $(\mathrm{RaSH})$ method led to the identification of 18 differentially expressed genes, among which was the homologue of the $N$. crassa clock modulator vivid, the translation elongation factor $1 \alpha$, and the transcriptional activator Hap1 [20]. Phenotypically, QM9978 forms less conidia than QM6a when grown on potato dextrose agar (PDA), fails to produce sufficient cellulases on any tested medium, and shows no growth when cultivated in liquid medium with cellulose as the sole carbon source [9, 20, 21] (Fig. 2).

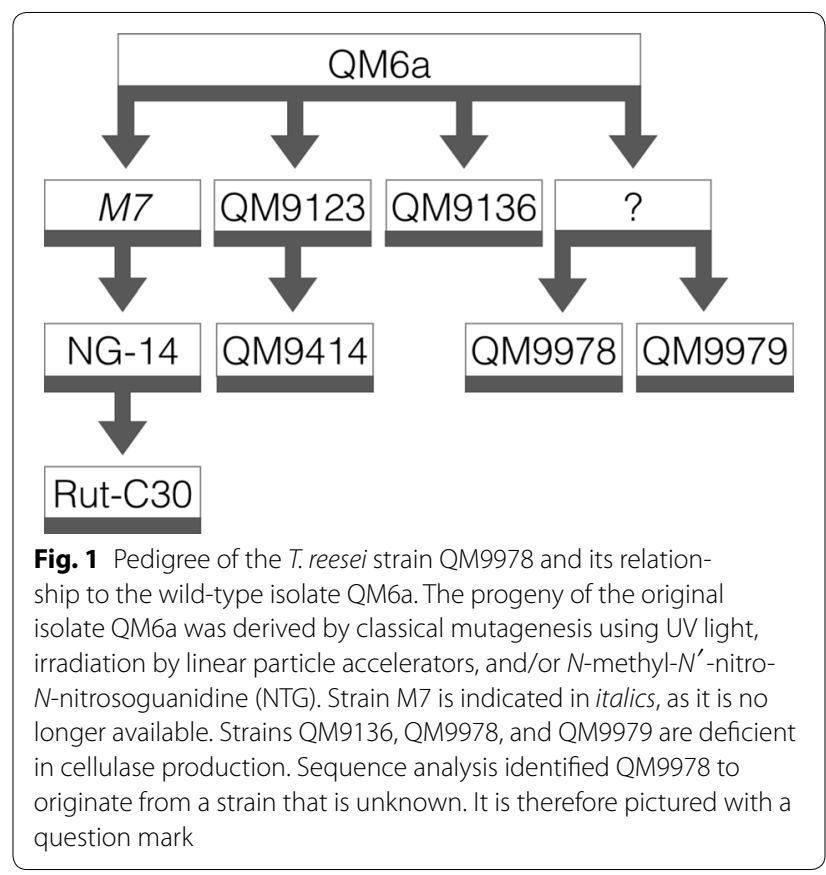


In an effort to identify new components of the cellulase gene regulation network of $T$. reesei, we used a whole genome sequencing and transcriptomic analysis approach comparing the cellulase-negative strain QM9978 to the wild-type strain QM6a. We show thatamong a few other mutations that were unlikely to have a significant impact on cellulase formation-this strain contains a chromosomal translocation upstream of the promoter region of the $N$. crassa homologue vib-1 (vegetative incompatibility blocked) and that vib1 expression in QM9978 is absent. The cellulase production in this strain can be restored by introduction of an additional $v i b 1$ copy and by vib1 overexpression. We further investigated the role of $v i b 1$ in the improved cellulase producer strains QM9414 and Rut-C30 and show that cellulase gene regulation in the three strains follows different regulatory pathways.

\section{Results}

\section{Genome analysis of QM9978}

To identify the genetic differences between QM6a and QM9978 leading to the cellulase-negative phenotype, we performed whole-genome high-throughput Illumina sequencing of QM9978 (for details, see "Methods" section). The comparative sequence analysis identified a total of 43 mutations in QM9978, of which 33 were found in the coding region of genes or in the assumed promoter (800 bp upstream) or terminator (200 bp downstream) region. Of those, 23 were characterized as SNVs (singlenucleotide variants), eight as InDels (small insertions and deletions), and two as deletions with 7 and $47 \mathrm{bp}$ missing, respectively (Table 1). They were located on 22

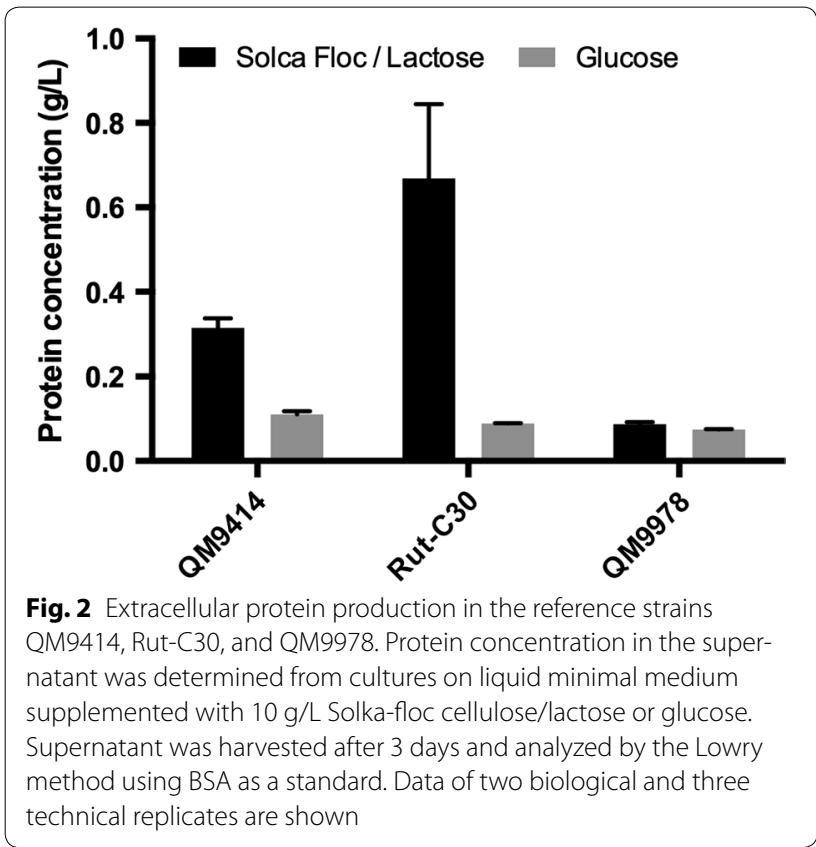

different scaffolds. The number of mutations in QM9978 is about three times higher than in QM9136, another QM6a derivative cellulase-negative strain used for the study of the cellulolytic system of T. reesei [18] (Fig. 1). Whole genome sequence analysis of QM9136 identified a truncation in the major cellulase regulator $x y r 1$ to be responsible for the cellulase-negative phenotype of this strain [18]. The gene encoding xyr1 in QM9978 is intact, and therefore another cause must exist for its disability to degrade cellulose.

Trichoderma reesei QM9123 was, until now, commonly believed to be the parental strain of QM9978. Since the genome sequence of QM9123 was published in 2010, we performed a comparison to QM9978 and showed that none of the 20 mutations identified in QM9123 is shared by QM9978 [16]. We therefore exclude the possibility that QM9123 is the parental strain of QM9978 and present an up-dated version of the T. reese $i$ strain lineage in Fig. 1. No detailed record on the generation of the strain QM9978 and the closely related strain QM9979, which is also cellulase negative, exists, but we assume that the high number of mutations is a result of two or more subsequent mutagenesis events. Sequence comparison of QM9978 to QM9979 showed common mutations between those two strains indicating that they originate from the same parental strain (F.B., personal communication). Compared to high cellulase producer strains like $T$. reesei NG14 (one InDel, 78 SNVs, and nine large structural variations) and Rut-C30 (one deletion, two InDels, and $106 \mathrm{SNVs}$ additional to NG14), the number of mutations is comparably low, probably because of alternative mutagenesis methods, and number and severity of treatments $[14,16,17,22]$.

From the 19 genes where a mutation occurred in the coding region, only the role of the blue-light receptor BLR1 in cellulase regulation has been studied in detail. Although BLR1 and BLR2 are the key regulators of the blue-light response in fungi and conidiation, it was shown that blr1 is not essential for cellulase expression [23] (Table 1).

Our research focused on the identified deletions and those mutations were subsequently verified by PCR analysis using primers flanking the deleted fragment. For two predicted deletions (on scaffold 1 and scaffold 16), we could not confirm the results obtained by Illumina sequencing as no PCR product was obtained. The recent genome assembly of $T$. reesei using chromosomal contact data in a computational approach identified scaffolds 1 and 16 to be located on chromosomes number five and seven, respectively [24-26]. Upon close examination of our sequencing data using the Integrative genome viewer program (http://software.broadinstitute. org/software/igv/) combined with the information on 
Table 1 Mutations found in T. reesei QM9978 compared to WT QM6a

\begin{tabular}{|c|c|c|c|c|c|c|}
\hline SNP_id & Mutation & Event & Position & Transcript & Element & Annotation \\
\hline 1_2509832 & SNV & $A>G$ & & Trire2:119839 & Intron & Putative cyanamide hydratase \\
\hline 1_753158 & SNV & $\mathrm{T}>\mathrm{G}$ & & Trire2:21170 & Intron & Putative $40 \mathrm{~S}$ ribosomal protein $\mathrm{S} 12$ \\
\hline 1_753159 & SNV & $C>T$ & & Trire2:119626 & Prom & Putative 40 S ribosomal protein $\$ 22$ \\
\hline 1_96633 & Transloc & $t(1 ; 16)(96,633 ; 631,551)$ & & Trire2:54675 & Upstream & Putative transcription factor VIB1 \\
\hline 10_21554 & InDel & $-1: G$ & +1671 & Trire2:121962 & Exon & Blue-light regulator 1 BRL1 \\
\hline $11 \_325040$ & SNV & $G>C$ & +583 & Trire2:4231 & Exon & Putative siderophore regulation protein \\
\hline 12_146369 & InDel & $-1: \mathrm{T}$ & & Trire2:108419 & Prom & Putative protein of unknown function \\
\hline 12_146369 & InDel & $-1: \mathrm{T}$ & & Trire2:122376 & Prom & Putative protein of unknown function \\
\hline 12_778518 & SNV & $\mathrm{T}>\mathrm{C}$ & & Trire2:108592 & Intron & Putative leucine aminopeptidase \\
\hline 12_842068 & SNV & $G>A$ & +776 & Trire2:79153 & Exon & Putative 5-oxoprolinase OXP1 \\
\hline 13_429746 & SNV & $G>A$ & & Trire2:79300 & Intron & Putative sphingolipid long chain base-responsive protein \\
\hline 13_839848 & SNV & $\mathrm{T}>\mathrm{C}$ & & No & & \\
\hline 14_189528 & InDel & $1: A$ & & Trire2:79485 & Term & Putative peptide $\mathrm{N}$-glycanase degradation \\
\hline $15 \_427120$ & SNV & $C>G$ & & Trire2:4767 & Prom & Putative biotin synthase \\
\hline 16_631551 & Transloc & $t(1 ; 16)(96,633 ; 631,551)$ & & Trire2:80028 & Upstream & Putative $A B C$ transporter \\
\hline 17_646809 & SNV & $G>T$ & & Trire2:65965 & Prom & $\begin{array}{l}\text { Putative S-adenosyl-L-methionine-dependent methyltrans- } \\
\text { ferase }\end{array}$ \\
\hline 20_145726 & SNV & $\mathrm{T}>\mathrm{C}$ & +293 & Trire2:55671 & Exon & Putative NAD(P)-binding Rossmann-fold domain protein \\
\hline 2_618372 & SNV & $C>T$ & +2098 & Trire2:66913 & Exon & Putative phosphatidylinositol 3-kinase \\
\hline 24_496758 & InDel & $-1: G$ & & Trire2:123658 & Intron & Putative guanylate-binding domain protein \\
\hline 26_169591 & SNV & $C G>A C$ & +2901 & Trire2:51893 & Exon & Putative lipid body protein ppoC \\
\hline 26_331506 & SNV & $G>A$ & & Trire2:68803 & Term & Putative RTA-1 domain protein \\
\hline 28_280867 & InDel & $-1: \mathrm{T}$ & & No & & \\
\hline 29_224118 & SNV & $\mathrm{T}>\mathrm{C}$ & & No & & \\
\hline 3_1061204 & InDel & $-7:$ ATATCAT & & No & & \\
\hline 3_1353739 & SNV & $G>A$ & +635 & Trire2:104458 & Exon & Putative protein of unknown function \\
\hline 31_146257 & SNV & $A>G$ & +427 & Trire2:69881 & Exon & Putative pyoverdine/dityrosine biosynthesis protein \\
\hline 33_52840 & InDel & $-1: \mathrm{T}$ & & No & & \\
\hline 37_85324 & SNV & $G>A$ & & Trire2:124181 & Intron & Putative DML1 protein \\
\hline 4_1236402 & SNV & $A>T$ & & No & & \\
\hline 4_1680892 & SNV & $G>A$ & +127 & Trire2:41761 & Exon & Putative vacuolar iron transporter \\
\hline 4_890445 & SNV & $A>T$ & & Trire2:75921 & Prom & Putative tRNA-dihydrouridine synthase 1 \\
\hline 4_890446 & SNV & $A>T$ & & Trire2:75921 & Prom & Putative tRNA-dihydrouridine synthase 1 \\
\hline 43_42477 & SNV & $G>A$ & +1144 & Trire2:6057 & Exon & Putative ubiquinol cytochrome-c reductase assembly protein \\
\hline 6_289426 & SNV & $G>T$ & & No & & \\
\hline 6_289431 & SNV & $C>G$ & & No & & \\
\hline 6_622255 & SNV & $G>C$ & & Trire2:105968 & Prom & Putative PcbC family protein \\
\hline 8_1174800 & InDel & $-7: G G A G G T C$ & & Trire2:39911 & Intron & $\begin{array}{l}\text { Putative S-adenosylmethionine-homocysteine methyltrans- } \\
\text { ferase }\end{array}$ \\
\hline 8_1290905 & InDel & $-1: A$ & +452 & Trire2:47897 & Exon & Putative $A B C$ transporter \\
\hline 9_1123734 & SNV & $G>T$ & & No & & \\
\hline 9_223955 & InDel & $-1: A$ & & Trire2:77836 & Prom & Putative protein of unknown function \\
\hline 9_475049 & InDel & $-1: G$ & & No & & \\
\hline
\end{tabular}

The SNP_id number gives the position on the scaffold as obtained by Illumina sequencing. The presented transcript ID corresponds to the protein ID in the JGI database (http://genome.jgi.doe.gov)

the Joint Genome Institute homepage (http://genome. jgi.doe.gov), it appeared that what we originally believed to be a deletion event could in reality be a translocation resulting from a chromosome break 1095 bp upstream of the ATG start codon of Trire2:54675 located on chromosome VII (Fig. 3a). To verify this hypothesis, we designed oligonucleotides flanking the assumed DNA break. Only PCRs with the primer combination 80028_MutaC_R 


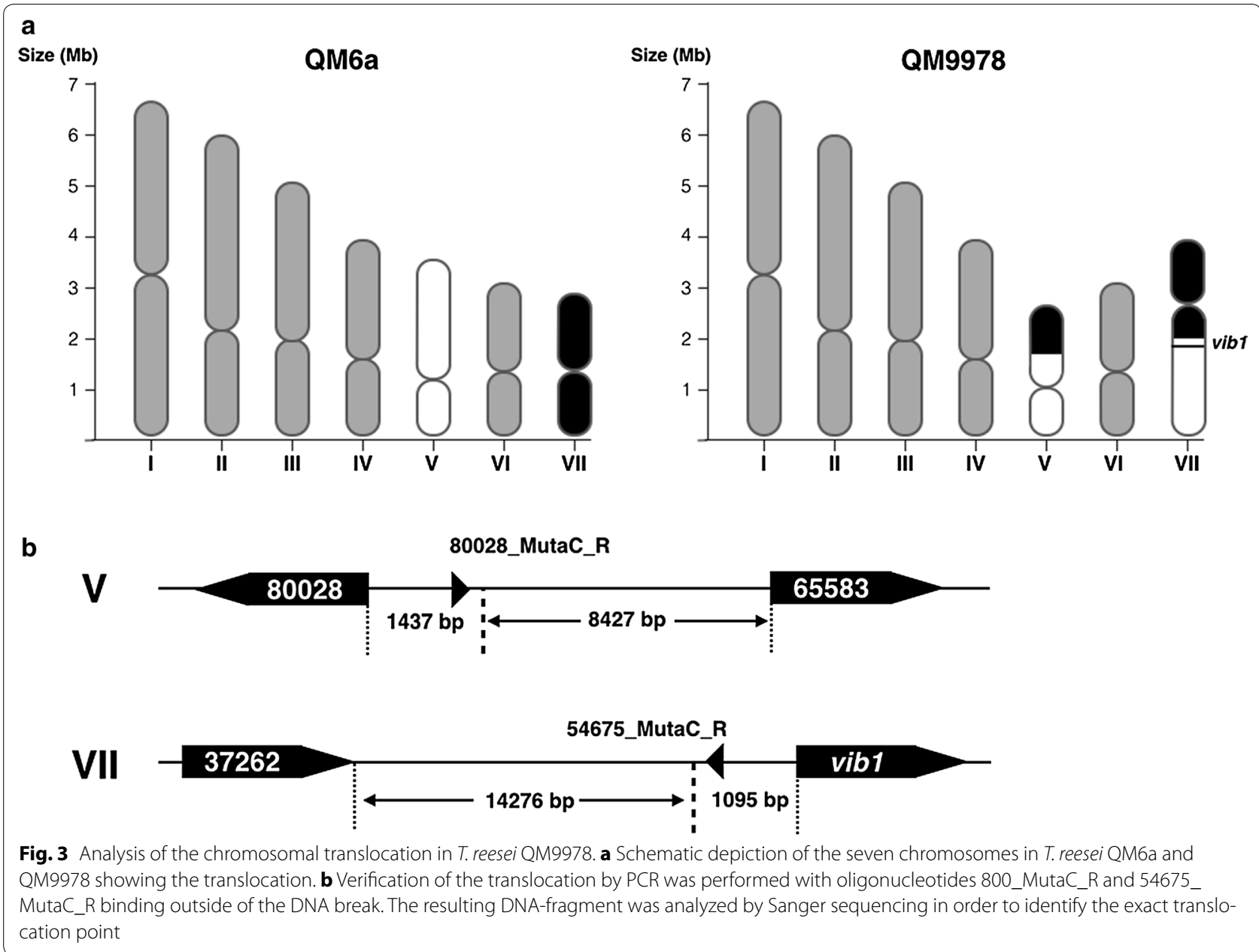

and 54675_MutaC_R binding on the two different chromosomes resulted in an amplicon (Fig. 3b). Sequencing of this amplicon identified the region where the DNA breaks occurred. As a result from the translocation, the gene Trire2:37262 (a putative ubiquitin-protein ligase) upstream from Trire2:54675 on chromosome VII is replaced by Trire2:80028, a putative $\mathrm{ABC}$ transporter on chromosome V (Fig. 3b).

\section{Gene expression profiling in T. reesei QM9978}

Changes in gene expression between QM9978 and QM6a were analyzed in order to define the impact of mutations at the transcriptional level. Strains were grown on D-glucose for approximately $24 \mathrm{~h}$ until the carbon source was depleted from the medium (less than $3 \mathrm{~g} / \mathrm{L}$ glucose remaining). Then, a lactose pulse of $10 \mathrm{~g} / \mathrm{L}$ was added to the medium as lactose is known to be a strong inducer of cellulases [27]. Total RNA of two biological replicates was extracted at three different time points: $0 \mathrm{~h}$ (after carbon source depletion and before lactose addition), 24 and $48 \mathrm{~h}$ after the lactose pulse. Statistical treatments and differential analyses were performed using DESeq 1.8.3. A threshold of two for the $\log 2$ ratios with an adjusted $p$ value $<0.001$ was used to identify genes differentially expressed (DE). Gene functions were identified by the aid of a manually annotated T.reesei genome database proprietary to IFPEN.

Comparison of the gene expression in QM9978 to QM6a identified a total of 785 genes differentially expressed (DE) in at least one time point. The number of down-regulated genes slightly increases during the time course, whereas the number of up-regulated genes remains stable. Interestingly, DE genes are mainly downregulated, meaning their expression is lower in QM9978 then in QM6a. We compared the gene expression data with our sequencing results and identified five DE genes, which were affected by mutations. The genes were characterized by homology search using the NCBI BLASTp tool (https://blast.ncbi.nlm.nih.gov/Blast.cgi) and the Joint Genome Institute genomics resource database (http://genome.jgi.doe.gov). The annotation was additionally verified manually using the FUNGIpath database 
(http://embg.igmors.u-psud.fr/fungipath/). This way we identified ID51893-an orthologue of the lipid body protein $\mathrm{ppoC}$ ( $A$. nidulans) involved in coordinating sexual and asexual sporulation [28], ID54675-a homologue of the transcription factor vib-1 involved in vegetative incompatibility and cellulose utilization in $N$. crassa [29], ID68803-a predicted RTA1-domain protein, and ID108418 and ID122376-two hypothetical proteins of unknown function.

From the total of 785 genes, only 153 genes (23\%) were $\mathrm{DE}$ at all time points. In this gene set, we find 14 glycoside hydrolases (including $\operatorname{cbh} 2, x y n 2$, and agl1), eight putative transporters (including $\operatorname{crt1} 1$ ), and four transcription factors including vib1 (ID54675) and azf1/sah-1 (ID61055) as identified by homology search as described above [30]. The N. crassa homologues of these two transcription factors have been shown to be involved in glucose signaling and to be up-regulated during growth on the silvergrass Miscanthus [31]. Of these, 153 genes two are impacted by mutation: vib1 and the putative RTA1domain protein (ID68803).

Among the four genes surrounding the translocation on chromosomes V and VII identified during our sequence analysis, only vib1 and Trire2:80028, a putative $A B C$ transporter whose expression is diminished in QM9978, show altered expression levels (Fig. 3).

Blastp analysis showed that T. reesei vib1 shows $49 \%$ similarity to $N$. crassa vib-1 $[29,32]$. Since $N$. crassa vib-1 has been shown to be essential for cellulase production in $N$. crassa, we investigated whether a link could be established between the translocation, vib1 expression, and the loss of cellulase production in the QM9978 strain.

\section{Analysis of the role of vib1 in cellulase induction Constitutive expression of vib1 restores cellulose utilization in QM9978}

To determine whether vib1 is involved in cellulose deconstruction by $T$. reesei, we constructed a vib1 overexpression QM9978 strain (QM9978 + vib1) by ectopic integration of the gene under the control of the strong constitutive promoter of $T$. reesei glyceraldehyde-3-phosphate dehydrogenase $(g p d)$ [33]. For two independent clones, we monitored enzyme production during 4 days using a fast screening assay based on azurine-crosslinked cellulose (AZCL-HE-cellulose) that releases a soluble blue dye into the agar medium after enzymatic hydrolysis by endoglucanases, in which the size of the blue halo on an agar plate corresponds to the amount of secreted cellulases. Plates supplemented with $10 \mathrm{~g} / \mathrm{L}$ glucose or lactose (for cellulase induction) and $1 \mathrm{~g} / \mathrm{L}$ AZCL-HE-cellulose were used and the results of one clone per strain are representatively shown in Fig. 4 and Additional file 1: Figure S1. Strain QM9978 failed to secrete a sufficient

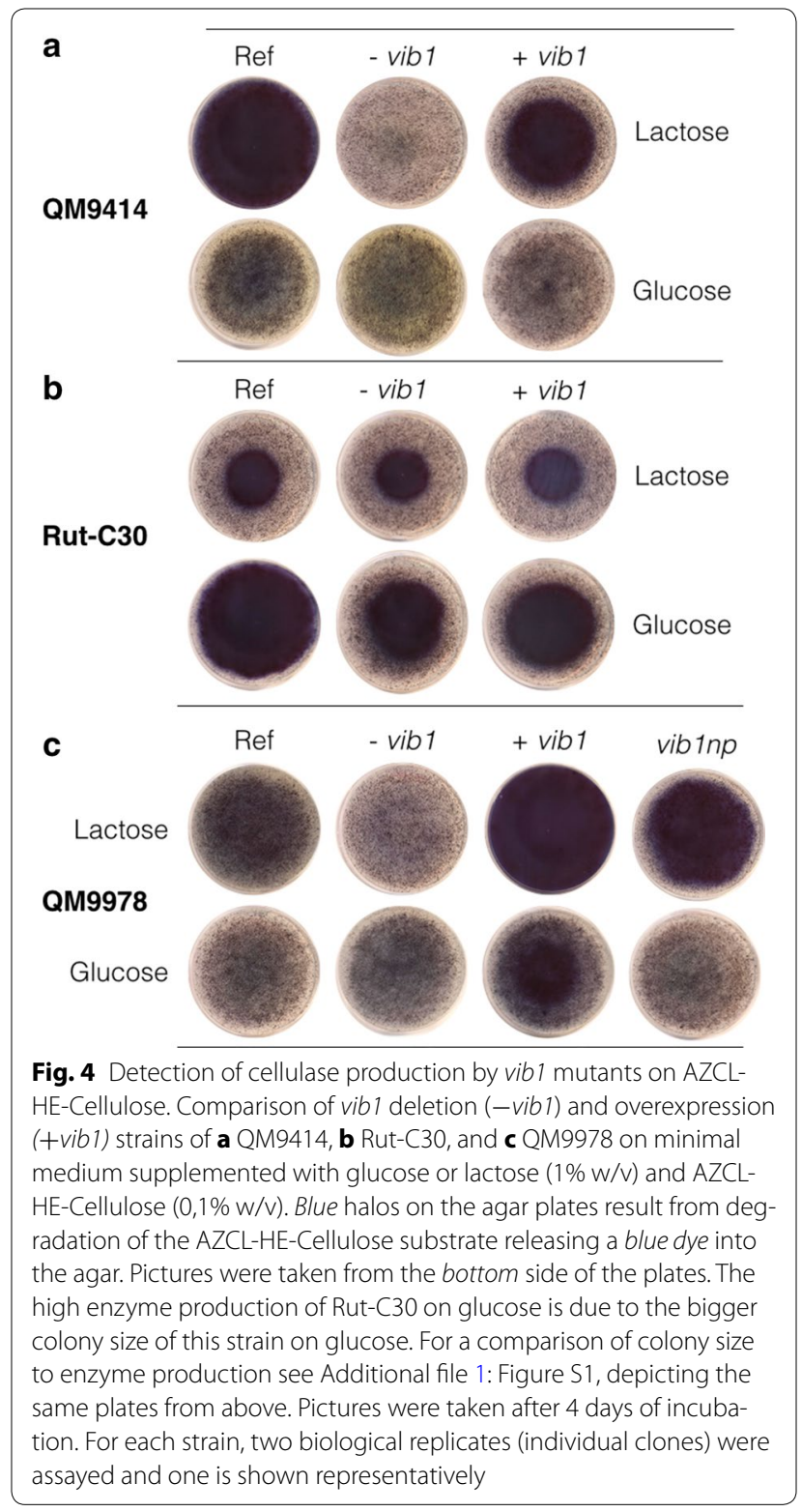

amount of cellulases on lactose to decompose the AZCLHE polymer, whereas the agar of the QM9978 + vib1 strain was stained blue due to enzymatic hydrolysis. To verify that no residual VIB1 activity remains in QM9978, we constructed the vib1 deletion strain QM9978 - vib1. Like QM9978, this strain was unable to decompose AZCL-HE-cellulose, indicating that the mutation in QM9978 equals a null phenotype (Fig. 3).

Since the data from the plate assay suggested a strong impact of vib1 on cellulase production, we produced liquid cultures grown on $10 \mathrm{~g} / \mathrm{L}$ lactose/Solka-floc (cellulase induction) and on $10 \mathrm{~g} / \mathrm{L}$ glucose (repression) to determine the protein content in the supernatant and the volumetric enzyme activity (see "Methods" for details on the 
protocol). Both the extracellular protein concentration and the filter paper activity were found to be significantly increased in strain QM9978 + vib1 compared to QM9978 $(p<0.0001$ and $p<0.01$, respectively) (Fig. 5).

The translocation in QM9978 occurred 1095 bp upstream of the vib1 ATG start codon. Therefore, the indicated promoter of approximately $1 \mathrm{~kb}$ remains unaffected [34, 35]. To test whether the abolished vib1 expression in QM9978 is due to the missing $5^{\prime}$ upstream region, we constructed a QM9978 strain expressing vib1 under the control of $850 \mathrm{bp}$ of its native promoter, ectopically integrated. This allowed us to investigate the role of the 5' region absent in QM9978, for example, if activator-binding sites were affected. The resulting strain QM9978_vib1np had an enzyme secretion capacity comparable to QM9978 + vib1 on plate test using AZCL-HE-cellulose (Fig. 4). These results were confirmed by real-time qPCR analysis, where we detected a significant accumulation of cbh1 (cel7a) transcript, both for the overexpression strain QM9978+vib1 and for QM9978_vib1np (Fig. 6a). Expression levels in both strains remained lower compared to strain QM9414, probably due to the fact that strain QM9414 has undergone a different mutagenesis treatment during strain engineering leading to higher expression of $c h b 1$ than a cellulase-restored QM9978 strain.

Analysis of vib1 transcription in QM9978 + vib1 and QM9978_vib1np confirmed that vib1 transcripts were present at levels equivalent to QM9414, a strain with unimpaired vib1 expression (Fig. 6b).

\section{vib1 deletion, but not overexpression, has an effect on cellulase induction in higher producer strains}

Strain QM9414 has been extensively used as a reference strain in the literature when comparing different mutations due to its capacity to produce a measurable amount of cellulases (QM6a producing cellulase levels below the detection limit of most assays). In addition to QM9414, we chose strain Rut-C30 as this is the highest enzyme producer strain (reported to produce $30 \mathrm{~g} / \mathrm{L}$ enzymes, depending on culture conditions) available for public research and is also used in industrial applications [36]. We performed our study in Rut-C30 to show if an industrial strain originating from the Rut lineage can be further improved by vib1 overexpression.

To gain a better understanding of the role that vib1 plays in cellulase induction we made use of the different genetic backgrounds of strain QM9414 and Rut-C30 and constructed the strains QM9414 \pm vib1 and RutC30 \pm vib1 by deleting vib1 or ectopically introducing an additional gene copy under the control of the strong constitutive gpd1 promoter, equivalent to the approach used in QM9978.

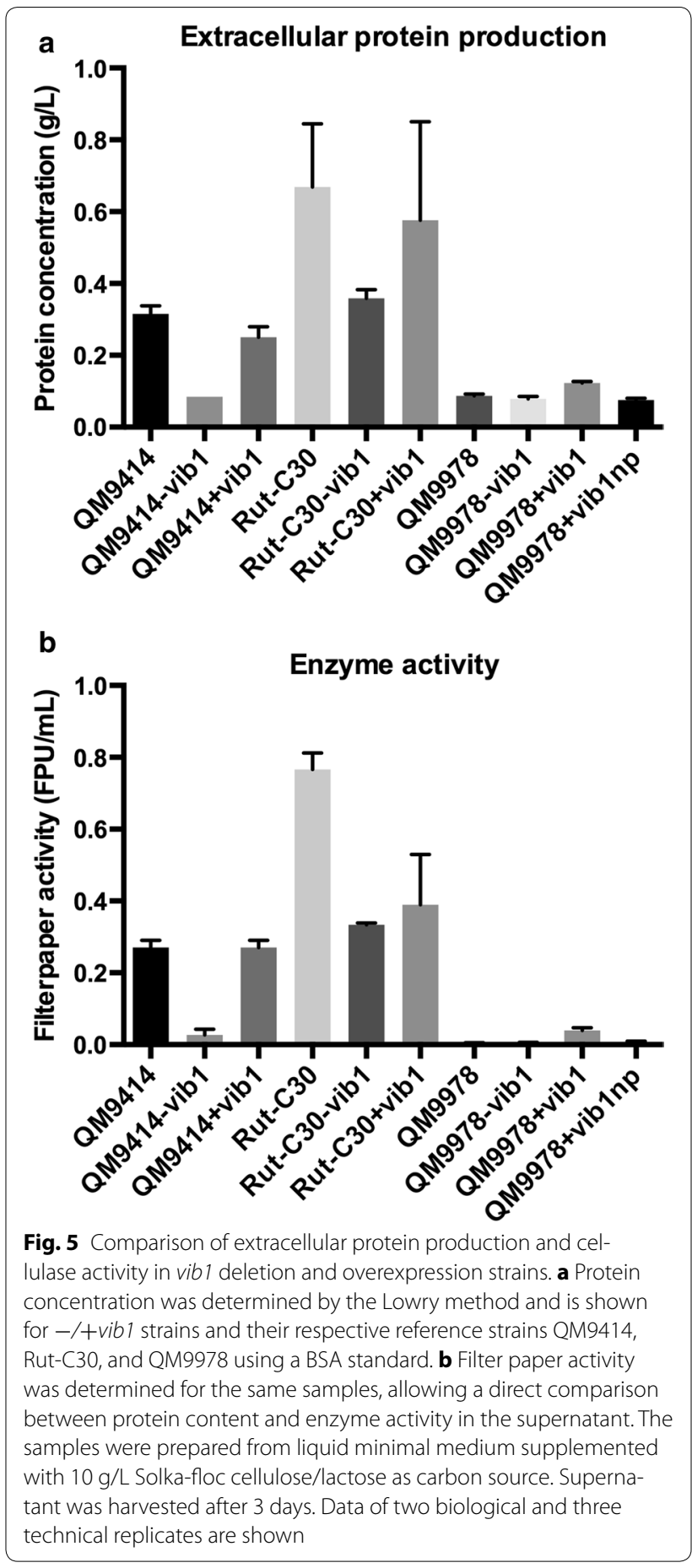

Screening on AZCL-HE-Cellulose revealed that vib1 deletion had a negative effect on cellulase production in QM9414 and Rut-C30, whereas no effects could be observed for the overexpression (Fig. 4). This finding was further confirmed by the measurement of extracellular protein concentration and enzyme activity in liquid 


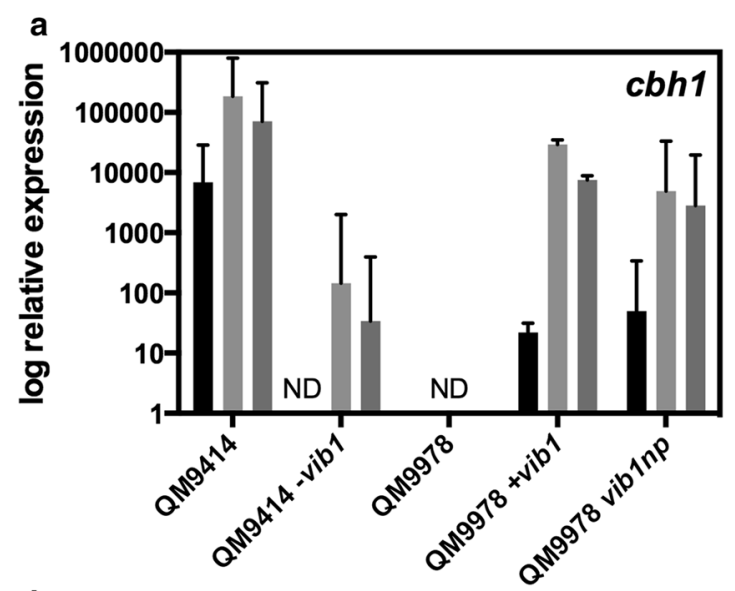

b
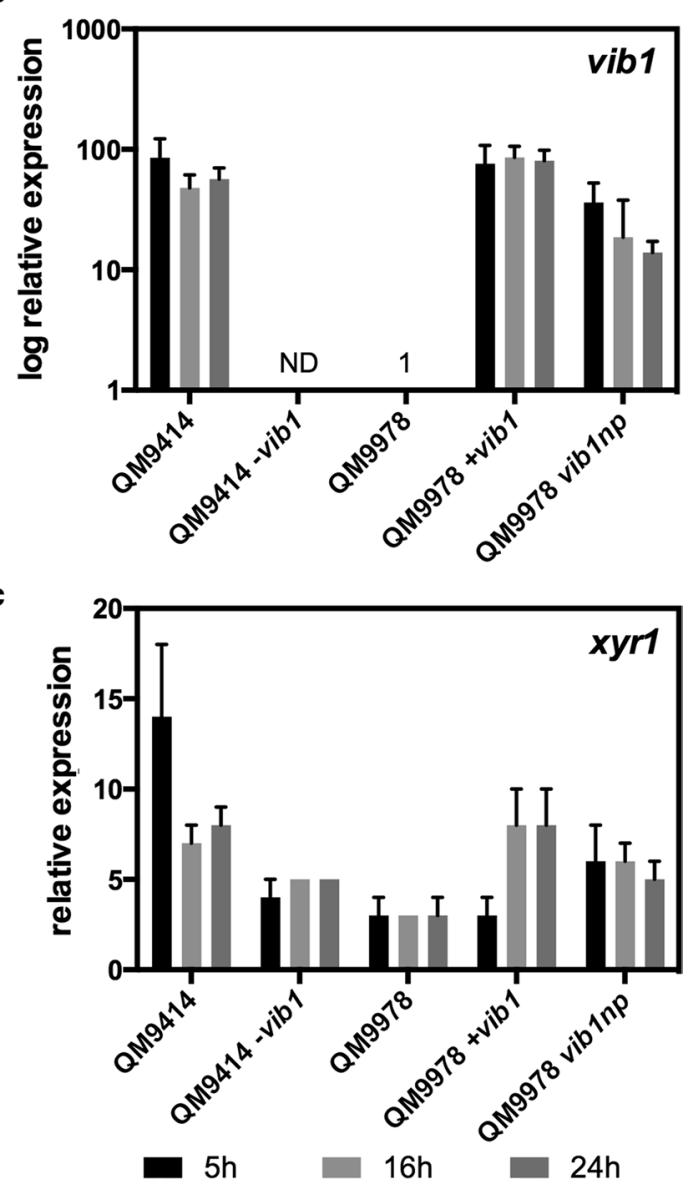

Fig. 6 VIB1 is required for cellulase production and signaling. Expression levels for the cellulase gene cbh $1 \mathbf{a}$, the transcription factor vib 1 $\mathbf{b}$, and the main positive regulator $x y r 1$ c were assessed in $-/+v i b 1$ strains versus WT after a shift from glycerol to $1 \%(\mathrm{v} / \mathrm{W})$ lactose. Gene expression levels were measured by relative quantitative PCR using tefl and sarl as a control and normalized to expression level at time point zero ( $24 \mathrm{~h}$ growth on glycerol) for $c b h 1$ and $x y r 1$ or to expression level in QM9978 for vib1. Samples were taken 5 h (black), $16 \mathrm{~h}$ (light gray), and $24 \mathrm{~h}$ (dark gray) after replacement. Mean values \pm standard error of triplicate data from two biological replicates are shown. ND not detected culture (minimal media supplemented with Solka-floc and lactose) and reflected in the reduced expression of cbh1 (cel7a) in the $\Delta v i b 1$ strains (Figs. 5, 6). We therefore conclude that overexpression of $v i b 1$ does not additionally improve cellulase production in those two strains.

Since previous studies have identified XYR1 as a major regulator of cellulase gene expression and $x y r 1$ deficiency to be linked to a cellulase-negative phenotype [37], we determined xyr1 transcript levels in the QM9978 and QM9414 strains. Deletion of vib1 in QM9414 significantly reduced xyr1 expression, whereas over-/expression of vib1 increased xyr1 levels in QM9978 $(p<0.001)$ (Fig. 6c). This finding indicates that XYR1 could function downstream of VIB1 and the reduced xyr1 expression could contribute to the cellulase-negative phenotype of $-v i b 1$ T. reesei strains.

\section{Discussion}

The manipulation of $T$. reese $i$ strains by random mutagenesis and subsequent selection procedures has led to the isolation of strains with cellulase production capacities surpassing $100 \mathrm{~g} / \mathrm{L}$ in industrial culture conditions [38]. The exact identification of the genetic changes that are responsible for the cellulase overproduction relied for a long time on laborious complementation studies, which were not very successful. Advances in high-throughput sequencing and genomic profiling have significantly contributed to a lower cost of these technologies and thus offer a feasible alternative for the identification of mutations [14, 16-18]. Strains obtained by random mutagenesis often contain a multitude of mutations, and genome analysis of QM9978 resulted in the identification of 33 mutations found in the coding region of genes or their promoters, plus four genes found in the region of a chromosomal rearrangement. In order to try and reduce the number of candidate genes responsible for the cellulasenegative phenotype, we combined the genome sequence analysis with a transcriptomic study in cellulase inducing conditions. This tandem approach and clues from existing literature about the role of N. crassa vib-1 in cellulase regulation led us to select vib1 as the main candidate, despite the fact that the coding region and the close-by intergenic regions of the gene were not affected by the mutagenesis [39]. A sequencing approach alone probably would not have resulted in vib1 being selected as prime candidate as the identified mutation is far away from the start codon. Considering distal genomic events and combining genome sequencing with a transcriptome analysis seems a robust approach for microbial strain "reverse-engineering."

Indeed, analysis of the genomic landscape led to the identification of a translocation between chromosomes $\mathrm{V}$ and VII. It has been shown that DNA damage such as 
double-strand breaks can lead to incompletely cleared sites of repair causing gene silencing through epigenetic events $[40,41]$. Histone modifications such as methylation, acetylation, or displacement are a common mechanism of gene regulation in filamentous fungi [42]. We speculated that the chromosome break led to histone modifications no longer favoring active transcription, since the translocation took place only $1 \mathrm{~kb}$ upstream of the vib1 start codon. Vib1 and Trire2:80028, a putative $\mathrm{ABC}$ transporter whose expression is also diminished in QM9978 when compared to QM6a, show altered expression levels. The other two genes involved (Trire2:65583 and Trire2:37262) are located at longer distances and therefore may be too far away to see their expression impacted (8427 and 14,276 bp, respectively, as compared to 1095 and $1437 \mathrm{bp}$ ). Another explanation would involve the rearrangement of regulator binding sequences (e.g., inhibitors of transcription) in the close proximity of the affected genes, thus having an unfavorable effect on gene expression.

Vib1 was initially identified in $N$. crassa, where it was shown to be required for vegetative incompatibility [29]. Since then, several studies have shown that vib1 and its homologs in other organisms are involved in the regulation of a diverse spectrum of metabolic processes including programmed cell death, antifungal compound production, and the response to carbon starvation, among others [43-46]. During a recent screening of a transcription factor deletion library in $N$. crassa, mutants unable to grow on cellulosic biomass were identified. Among them, vib-1 was shown to be essential for cellulose degradation. This finding led us to the assumption that vib1 may be involved in cellulase regulation in $T$. reesei, and the observed down-regulation in the QM9978 strain could be due to the relatively distal chromosomal translocation identified upstream. To rule out the possibility that the discovered balanced translocation deleted activator-binding sites positioned further upstream and which are required for active transcription of vib1, we reintroduced vib1 +850 bp as promoter sequence, which are not affected by the translocation. Since this approach could restore cellulase production, we conclude that despite a functional promoter and gene, the new genomic environment arising from the rearrangement is responsible for the loss of vib1 expression, either by epigenetic modifications or through other mechanisms involving, for example, the binding of distal transcriptional repressors.

Overexpression of vib1 in QM9978 restored enzyme secretion in this strain, and gene deletion in QM9414 abolished cellulase production, confirming that $v i b 1$ is required for cellulose degradation. Gene deletion in the industrial strain Rut-C30 resulted in reduced although not completely abolished cellulase production, indicating that additional factors contribute to cellulase induction, especially since overexpression of $v i b 1$ had no effect on cellulase production for QM9414 and Rut-C30. We therefore conclude that $v i b 1$ is not suitable for the amelioration of hyper-producing strains, as they probably already accumulated other mutations masking the effect of $v i b 1$ overexpression.

The exact role of the different transcription factors in $T$. reesei during cellulase induction is not fully understood yet. Although most of the cellulase genes are regulated in a coordinated way, their relative expression levels differ in higher producers [47]. Overexpression or constitutive activation of xyr1 lead to a significant elevation/deregulation of xylanase transcription levels and had an impact on cellulase induction in other studies $[48,49]$.

Our transcriptional analysis showed differential regulation of the main positive regulator xyr1 depending on $v i b 1$ expression. We observed no significant changes in $x y r 1$ expression during cultivation on lactose, which is consistent with recent findings where xyrl induction does not require metabolism of D-galactose $[50,51]$. The significantly reduced expression of $x y r 1$ in $-v i b 1$ strains could contribute to the cellulase-negative phenotype of QM9978, as xyr1 deletion has been shown to abolish cellulase induction on cellulose and sophorose and to impair the induction of hemicellulase genes involved in xylan and arabinan degradation in T. reesei, N. crassa, and A. niger [52-54]. Since xyr1 expression in QM9978 and QM9414 - vib1 is only reduced and not completely abolished, other factors besides VIB1 must be involved in its regulation and in cellulase gene expression.

A recent model for cellulase regulation in $N$. crassa proposes the involvement of several conserved transcription factors and shows that VIB-1 functions upstream of the inducing signal, repressing CRE1 and COL26 and thus inducing CLR-1 and CLR-2 $[39,55,56]$ to promote cellulase production. The $T$. reese $i$ homologue of CLR-2 was found to be significantly up-regulated during growth on lactose but a detailed analysis of its function is still missing [50, 57]. Overexpression of clr2 in QM9414 has shown that $c l r 2$ (gene 26163 in the respective study) had only a minor effect on cellulase production in $T$. reesei, and a homologue of $c l r-1$, which is essential for cellulase production on $N$. crassa, is missing in T. reesei [13]. BglR, the COL26 homologue of T. reesei, was not regulated during growth on lactose in our study, neither in the QM6a wild type nor in QM9978. A recent study identified col-26 to be involved in starch signaling in $N$. crassa but no data are available yet for T. reesei [58]. Our transcriptomic analysis showed no difference in $b g l R$ expression in strains expressing/not expressing vib1. We therefore cannot conclude that $b g l R$ plays a major role in 
vib1 downstream signaling in $T$. reesei. Whether a synergy between $c r e 1, b g l R$, and $v i b 1$ exists in $T$. reesei, like it does in $N$. crassa, remains for the moment unclear. Transcriptomic analysis performed previously by our lab on strains NG14 and RUT-C30 shows an enhanced expression of vib1 in RUT-C30 during growth on lactose [59]. Since the major difference between NG14 and RUTC30 is a partial deletion of cre1 in RUT-C30, it may be speculated that in $T$. reesei, contrary to $N$. crassa, vib1 acts downstream of the inducing signal, which would also explain why $b g l R$ is not differentially expressed in a $\Delta v i b 1$ background.

In a study performed by Schmoll et al., 18 genes specifically expressed in QM9978 compared to QM9414 were identified [20]. From those genes, we find six which are differentially expressed in our study. The differences in experimental conditions and reference strains may explain why a different gene set was identified by Schmoll et al. compared to our analysis and why vib1 was not detected as differentially expressed.

\section{Conclusions}

Our analysis used genomic data in combination with gene expression analysis and revealed a chromosomal recombination event to be responsible for the cellulase-negative phenotype of QM9978. We identified VIB1 as a transcription factor required for the degradation of lignocellulosic biomass whose expression is absent in QM9978. Deletion of vib1 leads to a defect in cellulase production in different improved cellulase producer strains, whereas overexpression had no influence on cellulase expression. These results confirm that vib1 is an important component of the cellulase regulon in $N$. crassa and $T$. reesei, but the precise function of $v i b 1$ in the regulatory network of T. reese $i$ needs to be further examined ([39], this study). However, since straightforward overexpression did not increase the production, a more detailed understanding of the regulatory mechanisms would be required to make this transcription factor interesting for industrial applications by gene engineering strain improvement. Our study demonstrates the importance of studying cellulase-negative strains complementary to high-producing strains for the understanding of the cellulase gene regulation process. It is, to our knowledge, the first report of a distal chromosomal rearrangement in a biotechnology-relevant strain affecting an otherwise intact promoter-gene system, thus provoking a dramatic phenotype. These phenomena should not be overlooked during genome-wide analysis of strains, which often focus on point mutations and InDels.

\section{Methods}

Fungal strains, culture conditions, and measurement of cellulase formation

Trichoderma reesei wild-type strain QM6a (ATCC 13631), the early cellulase producing mutant $T$. reesei QM9414 (ATCC 26921), the cellulase-negative mutant QM9978 (obtained originally from Dr. K.O' Donnell, U.S. Department of Agriculture, Peoria, IL), and the hypercellulosic strain Rut-C30 (ATCC 56765) were used throughout this study and kept on potato dextrose agar (Sigma, St. Louis, MO) at $30{ }^{\circ} \mathrm{C}$ (Additional file 2: Table S1). T. reese $i$ was grown in liquid culture in 250-mL Erlenmeyer flasks on a rotary shaker $(250 \mathrm{rpm})$ at $30{ }^{\circ} \mathrm{C}$ in $50 \mathrm{~mL}$ minimal medium as described [60] using frozen spores as inoculum. Carbon sources used are specified in the legends to the respective figures, and were used as $1 \%(\mathrm{w} / \mathrm{v})$ in batch cultures. To assess the cellulase formation on different carbon sources using a colorimetric assay based on AZCL-HE-cellulose, strains were grown on minimal medium plates supplemented with $5 \mathrm{~g} / \mathrm{L}$ of the respective carbon source in addition to AZCL-HE-cellulose (Megazyme International, Ireland) to a concentration of $1 \mathrm{~g} / \mathrm{L}$. Determination of protein content in culture supernatants was assessed by the modified Lowry protein assay as described using three biological and at least two technical replicates [61]. Global cellulase activity was measured using the IUPAC standard Filter Paper Assay [62], after a 15-fold miniaturization similar to [63] which allowed working in 2-mL Eppendorf tubes. In order to surround the desired $4 \%$ conversion yield, four enzyme dilutions were tested for each sample. This miniaturized protocol was validated by comparison with the standard protocol. Statistical analysis of the results was performed with the Prism GraphPad software (https://www.graphpad.com/ scientific-software/prism/).

For transcriptomic studies $50 \mathrm{~mL}$ of minimal medium $\left(5 \mathrm{~g} / \mathrm{L}\left(\mathrm{NH}_{4}\right)_{2} \mathrm{SO}_{4}, 5 \mathrm{~g} / \mathrm{L} \mathrm{KH}_{2} \mathrm{PO}_{4}, 11.7 \mathrm{~g} / \mathrm{L}\right.$ trisodium citrate, $0.6 \mathrm{~g} / \mathrm{L} \mathrm{MgSO}_{4}, 0.6 \mathrm{~g} \mathrm{CaCl}_{2}, 20 \mathrm{~g} / \mathrm{L}$ glucose) were prepared in a $250-\mathrm{mL}$ Erlenmeyer flask. The medium was supplemented with the following trace elements: $0.5 \mathrm{~mL} / \mathrm{L}$ FeSO $4 \cdot 7 \mathrm{H}_{2} \mathrm{O}, 2 \mathrm{~mL} / \mathrm{L} \quad \mathrm{CoCl}_{2}, 0.16 \mathrm{~mL} / \mathrm{L}$ $\mathrm{MnSO}_{4}$, and $0.14 \mathrm{~mL} / \mathrm{L} \mathrm{ZnSO}_{4}$. Prior to sterilization, the $\mathrm{pH}$ of the medium was adjusted to 5.4. Strains QM6a and QM9978 were inoculated in duplicate with approx $10^{6}$ conidia/mL. Cultivation was carried out at $30{ }^{\circ} \mathrm{C}$ at $150 \mathrm{rpm}$. When the glucose was close to depletion $(<3 \mathrm{~g} / \mathrm{L}), 5 \mathrm{~mL}$ of a lactose solution was added $(25 \mathrm{~g} / \mathrm{L}$ lactose, $6 \mathrm{~g} / \mathrm{L}\left(\mathrm{NH}_{4}\right)_{2} \mathrm{SO}_{4}, 5 \mathrm{~g} / \mathrm{L}$ trisodium citrate). Glucose concentration was assessed by enzymatic reaction using an analox glucose analyzer GM10 (Imlab). Extracellular protein concentration was measured against a BSA standard (0-1.5 g/L range with second-order 
regression) using the Quick Start Bradford Protein Assay kit (Bio-Rad).

To monitor gene expression levels via real-time qPCR, the replacement technique described by Sternberg and Mandels [64] was used: mycelia, grown for $24 \mathrm{~h}$ on $1 \%$ $(\mathrm{w} / \mathrm{v})$ glycerol as the carbon source under otherwise similar conditions as described above, were cautiously filtered through Miracloth (Calbiochem, EMD Biosciences, La Jolla, CA), washed with tap water, and resuspended in minimal medium supplemented with the respective carbon source at $1 \%(\mathrm{w} / \mathrm{v})$ and the incubation continued for 5,16 , and $24 \mathrm{~h}$. To guarantee equal treatment of the cultures, they were done in parallel and results of three technical replicates were obtained.

Escherichia coli NEB 10-beta competent cells (New England Biolabs, France) were used for the propagation of vector molecules and DNA manipulations.

\section{Vector construction for generation of gene deletion and overexpression mutants}

Deletion cassettes consisting of 1-1.5 kb fragments of the gene specific flanking regions interrupted by the hygromycin resistance cassette were assembled by yeast recombinational cloning [50, 65]. Oligonucleotides $(10 \mathrm{mM}) 5 \mathrm{~F}+3 \mathrm{R}$ and $3 \mathrm{~F}+3 \mathrm{R}$ were used for amplification of the individual flanking regions from genomic $T$. reesei DNA using Phusion polymerase (Thermo Fisher Scientific). Approximately $19 \mathrm{bp}$ that overlap with the pRS426 (URA +) yeast shuttle vector or the $h p h$ gene were introduced by PCR at each flanking end to allow homologous recombination. The hph marker cassette was amplified from pLHhph1 with oligonucleotides hphF and hphR [65]. A PCR touchdown program ranging from 62 to $58^{\circ} \mathrm{C}$ for annealing was used for amplification. Oligonucleotide sequences are shown in Additional file 3: Table S2. Yeast transformation was performed as described [66] using the lithium chloride/polyethylene glycol procedure. Yeast strain WW-YH10 (ATCC 208405) was transformed with both flanking regions, the $h p h$ marker cassette and an EcoRI/XbaI-digested plasmid pRS426 [67]. Transformants were selected on synthetic complete dropout medium (SC-URA with uracil dropped out). Following total DNA isolation from liquid SC-URA medium, plasmids were introduced into chemically competent NEB 10-beta E. coli cells (New England Biolabs) [68]. The outside primers $5 \mathrm{~F}+3 \mathrm{R}$ were used to synthesize the complete deletion cassette from plasmids isolated from S. cerevisiae.

For construction of overexpressing strains, the coding region of vib1 was amplified using oligonucleotides VIB1 for and VIB1 rev and placed under the control of the strong constitutive $g p d$ promoter (oligonucleotides promGPD for and PromGPD rev) followed by the gpd terminator (termGPD for and termGPD rev) and the $h p h$ resistance cassette (hph for and hph rev, see Additional file 3: Table S2) all inserted into the $X b a \mathrm{I} / E c o R I-l i n e-$ arized plasmid pUC19 yielding plasmid pUC_vib1_OE. Oligonucleotides K7 VIB1 for and K7 VIB1 rev were used to amplify the complete overexpression cassette from pUC_vib1_OE.

For reintroduction of vib1 under the control of the native promoter into the strain QM9978, the coding region plus approximately $850 \mathrm{bp}$ of the promoter region (after the translocation breakpoint) together with $500 \mathrm{bp}$ of the terminator region were amplified using oligonucleotides VIB1_F and VIB1_R (Additional file 3: Table S2) and introduced in the SacI/BamHI-linearized plasmid pLHhph1 using the Gibson Assembly Cloning Kit (New England Biolabs) [65]. Five micrograms of the circular plasmid were used for protoplast transformation of $T$. reesei.

\section{Transformation of $T$. reesei and analysis of transformants}

Trichoderma reesei QM9414, QM9978, and Rut-C30 were used for the generation of vib1 deletion and overexpression strains. Protoplast preparation and transformation were performed as previously described [69]. The deletion cassettes were purified after PCR (QIAquick PCR Purification kit, QIAGEN) and concentrations were determined (Nanodrop Spectrophotometer, Peqlab). After transformation protoplasts were stabilized and regenerated on selection medium supplemented with $100 \mathrm{mg} / \mathrm{mL}$ hygromycin B. For sporulation, transformants were transferred to 12-well plates and purified by plating conidiospores onto plates with $0.1 \%$ Triton X-100 as colony restrictor. Single colonies were transferred to selective medium and screened for correct integration of the deletion or overexpression cassettes by PCR analysis (primer abbreviated with "ch" in Additional file 3: Table $\mathrm{S} 2)$. Insertion of the $g p d$-vib1 overexpression cassette was verified with primer pairs TR46-verif $5^{\prime}$ vib1 for + TR47verif $5^{\prime}$ vib1 rev, TR48-verif $3^{\prime}$ vib1 for + TR49-verif 3'vib1 rev, and TR50-verif hph vib1 for + TR51-verif hph vib1 rev amplifying the $5^{\prime}$ or $3^{\prime}$ region and the $h p h$ marker gene, respectively. Three or four independent clones were isolated for each strain construction and analyzed as biological replicates.

\section{Gene expression analysis by real-time qPCR}

DNase treated (DNase I, RNase free; Fermentas) RNA $(5 \mathrm{mg})$ was reverse transcribed with the RevertAidTM First Strand cDNA Kit (Fermentas, Germany) according to the manufacturer's protocol using a combination (1:1) of the provided oligo-dT and random hexamer primers. All assays were carried out in 96-well plates, which were covered with optical tape, as previously described [70]. 
Primers, amplification efficiency, and R-square values are given in Additional file 4: Table S3. The amplification efficiency was determined using triplicate reactions from a dilution series of cDNA, and then calculated from the given slopes in the IQ5 Optical system Software v2.0. Expression ratios were calculated using the REST 2009 Software (Quiagen, Germany). All samples were analyzed in two independent experiments with three replicates in each run.

\section{RNA sample preparation}

At each time point, $5 \mathrm{~mL}$ culture medium containing mycelia was filtrated on $1.2-\mu \mathrm{L}$ GF/C glass microfiber membranes and flash frozen in liquid nitrogen. Frozen mycelia were disrupted and homogenized in Lysing Matrix C (Fast RNA Pro Red Kit, MP Bio) in the presence of $700 \mu \mathrm{L}$ Lysis buffer RLT (RNeasy Mini Kit, Qiagen) complemented with $7 \mu \mathrm{L}$ of $\beta$-mercaptoethanol on a rotor-stator homogenizer (FastPrep, MP Bio, Santa Ana, CA, USA). After centrifugation, the lysate was transferred on a Qiashredder spin column (Qiagen) and centrifuged for $2 \mathrm{~min}$ to eliminate all cell debris. The flow-through was then mixed with 0.5 volumes of pure ethanol and transferred to an RNeasy spin column. All further steps, including an on-column DNAse digestion, were realized following the manufacturer's instructions. RNA quantification was performed with Qubit 2.0 (Life Technologies, Carlsbad, CA, USA). The quantity and quality of the total RNA was determined using a NanoDrop ND-1000 spectrophotometer (Nanodrop Technologies, Wilmington, USA) and by electrophoresis on $1 \%$ agarose gel. An additional quality control was performed on the Bioanalyzer 2100 system (Agilent, Santa Clara, USA).

\section{RNA-seq library preparation and analysis}

Library preparation and Illumina sequencing were performed at the Ecole normale superieure genomic platform (Paris, France). Messenger (polyA+) RNAs were purified from $1 \mu \mathrm{g}$ of total RNA using oligo(dT) primer. Libraries were prepared using the strand non-specific RNA-Seq library preparation TruSeq RNA Sample Prep Kits v1 (Illumina). Libraries were multiplexed by four on one single flowcell lane and subjected to 50-bp pairedend read sequencing on a HiSeq 1500 device. A mean of $52 \pm 10$ million passing Illumina quality filter reads was obtained for each of all the samples. We performed RNAseq analysis using the Eoulsan pipeline [71]. Only read 1 was considered for the further analyses. Before mapping, poly $\mathrm{N}$ read tails were trimmed, reads $\leq 11$ bases were removed, and reads with quality mean $\leq 12$ were discarded. Reads were then aligned against the $T$. reesei genome (version 2 from the JGI website) using the Bowtie mapper (version 0.12.7) [72]. Alignments from reads matching more than once on the reference genome were removed using Java version of samtools [73]. To compute gene expression, the $T$. reesei genome annotation from JGI (version 2) was used. All overlapping regions between alignments and referenced exons were counted. The sample counts were normalized using DESeq 1.8.3 [74]. Statistical treatments and differential analyses were also performed using DESeq 1.8.3. A threshold of two for the $\log 2$ ratios with an adjusted $p$ value $<0.001$ was used to identify genes differentially expressed (DE). Gene functions were identified by the aid of a manually annotated T. reesei genome database proprietary to IFPEN.

The RNA-Seq gene expression data and raw fastq files are available at the GEO repository (http://www.ncbi. nlm.nih.gov.gate1.inist.fr/geo/) under Accession Number GSE89199.

\section{Illumina genome sequencing of T. reesei QM9978}

Chromosomal DNA from T. reesei QM9978 was prepared as previously described [14]. Fragment libraries were prepared according to the TruSeq ${ }^{\circledR}$ DNA Sample Preparation Guide from Illumina (http://www.illumina. com). These libraries were then loaded onto the cluster generation station for single-molecule bridge amplification using the Standard Cluster Generation kit from Illumina. The slide with amplified clusters was then subjected to sequencing on the Illumina Genome Analyser I (GAI) for single reads using the 36 cycle Sequencing Kit version 1 from Illumina.

The whole genome sequence of $T$. reesei QM9978 will be deposited at the Sequence Read Archive (SRA; http:// www.ncbi.nlm.nih.gov/sra).

\section{Sequence alignment and analyses}

Illumina short reads from QM9978 were mapped onto the T. reesei genome (http://genome.jgi-psf.org/Trire2/), using the Maq 0.6.6 software solution [75]. Mapping was done with two maximum mismatches. InDels and SNVs were identified using Maq 0.6.6. Homozygous mutations were selected and filtered on genomic context (complexity $=1$, uniqueness $>15.8$, GC percentage between 0.31 and 0.74$)$. Each mutation was manually checked using the Integrative Genome Viewer and compared to the sequence of the Rut lineage to remove the false mutations coming from initial QM6a error sequencing. Large structural variations were searched using the BreakDancer software and filtered on the reads number covering the genomic variations [76].

We evaluated the location of SNVs and deletions according to gene annotations using the "filtered models" from the JGI website. From this annotation, we 
calculated the position of intron, promoter (using an 800 bp upstream region), and terminator (using a 200-bp downstream region).

Functions of genes were predicted by similarity to orthologous genes when found in other fungal taxa using the FUNGIpath database (http://embg.igmors.u-psud. fr/fungipath/). If no orthologous gene function could be identified but a gene with a homology e-value superior to e-10 was identified, the product of this gene was annotated as "similar to." Conserved domains were identified either by interproscan (http://www.ebi.ac.uk/interpro/ search/sequence-search) or by NCBI BLASTp search (https://blast.ncbi.nlm.nih.gov/Blast.cgi).

To validate the translocation between chromosomes $\mathrm{V}$ and VII, we amplified the region around genes encoded by the protein IDs 80028 and 54675 by PCR using oligonucleotides up and downstream of the coding region (Primer 54675_MutaC_F + 54675_MutaC_R and 80028_ MutaC_F + 80028_MutaC_R Fig. 3b; Additional file 3: Table S2). PCR amplicons were sequenced with adequate primers using Sanger cycle sequencing/capillary electrophoresis (Microsynth AG, Austria).

\section{Additional files}

Additional file 1: Figure S1. Growth analysis of vib1 mutant strains on AZCL-HE-Cellulose. The images correspond to Fig. 4 showing the enzyme production by the strains on AZCL-HE-Cellulose supplemented with 10 $\mathrm{g} / \mathrm{L}$ lactose or glucose. Comparison of colony size to cellulose degradation shows that strains QM9978 and QM9414 -vib1 impaired in cellulase production are still able to grow on lactose. Pictures were taken after 4 days of incubation. For each strain two biological replicates (individual clones) were assayed and one is shown representatively.

Additional file 2: Table S1. Strains used throughout the study.

Additional file 3: Table S2. Oligonucleotides used in this study.

Additional file 4: Table S3. Oligonucleotides used for quantitative realtime $\mathrm{qPCR}$ analysis.

\section{Author details}

${ }^{1}$ IFP Energies Nouvelles, 1-4 Avenue de Bois-Préau, 92852 Rueil-Malmaison, France. ${ }^{2}$ Molecular Biotechnology, Research Division Biochemical Technology, Institute of Chemical Engineering, TU-Wien, 1060 Vienna, Austria. ${ }^{3}$ Earth and Biological Sciences Directorate, Pacific Northwest National Laboratory, Richland, WA 99354, USA. ${ }^{4}$ Evolution Paris Seine-Institut de Biologie Paris Seine (EPS-IBPS), Sorbonne Universités, UPMC Univ Paris 06, Univ Antilles, Univ Nice Sophia Antipolis, CNRS, 75005 Paris, France. ${ }^{5}$ École normale supérieure, PSL Research University, CNRS, Inserm, Institut de Biologie de l'École normale supérieure (IBENS), Plateforme Génomique, 75005 Paris, France. ${ }^{6}$ Present Address: Genetics of Biofilms Unit, Department of Microbiology, Institut Pasteur, 25-28 Rue du Dr Roux, 75015 Paris, France.

\section{Acknowledgements}

The authors would like to thank Etienne Jourdier and Celine Cohen for their help during enzyme activity measurements and Professor Christian P. Kubicek for providing the cellulase-negative strain QM9978 on which this study was based.

\section{Competing interests}

The authors declare that they have no competing interests.

\section{Availability of supporting data}

The whole genome sequence of T. reesei QM9978 is deposited at the Sequence Read Archive (SRA; https://www.ncbi.nlm.nih.gov/sra) under the Accession Number SRX2015251.

The RNA-Seq gene expression data and raw fasta files are available at the GEO repository (http://www.ncbi.nlm.nih.gov.gate1.inist.fr/geo/) under the Accession Number GSE89199.

\section{Consent for publication}

Not applicable.

\section{Ethical approval and consent to participate}

Not applicable.

\section{Funding}

This work has been supported by the Austrian Science Fund (P24219-B21) to BS. JR was further supported by the TU Wien Ph.D. program molecular and elemental imaging in biosciences MEIBio.

The École normale supérieure genomic platform was supported by the France Génomique national infrastructure, funded as part of the "Investissements d'Avenir" program managed by the Agence Nationale de la Recherche (contract ANR-10-INBS-09).

This work was in part supported by the "Fondation Tuck" research fund (Grant 2009-03) to AM, SLC, and FBM.

\section{Publisher's Note}

Springer Nature remains neutral with regard to jurisdictional claims in published maps and institutional affiliations.

Received: 15 December 2016 Accepted: 29 August 2017

Published online: 07 September 2017

\section{References}

1. Liu G, Qin Y, Li Z, Qu Y. Development of highly efficient, low-cost lignocellulolytic enzyme systems in the post-genomic era. Biotechnol Adv. 2013;31:962-75.

2. Bouws $H$, Wattenberg $A$, Zorn $H$. Fungal secretomes-nature's toolbox for white biotechnology. Appl Microbiol Biotechnol. 2008:80:381-8.

3. Druzhinina IS, Seidl-Seiboth V, Herrera-Estrella A, Horwitz BA, Kenerley CM, Monte E, Mukherjee PK, Zeilinger S, Grigoriev IV, Kubicek CP. Trichoderma: the genomics of opportunistic success. Nat Rev Microbiol. 2011:9:749-59. 
4. Reese ET. History of the cellulase program at the U.S. army Natick Development Center. Biotechnol Bioeng Symp. 1976;6:9-20.

5. Kubicek CP, Herrera-Estrella A, Seidl-Seiboth V, Martinez DA, Druzhinina IS, Thon M, Zeilinger S, Casas-Flores S, Horwitz BA, Mukherjee PK, et al. Comparative genome sequence analysis underscores mycoparasitism as the ancestral life style of Trichoderma. Genome Biol. 2011;12:R40.

6. Bayer EA. Remembering Mary (1917 to 2008): editorial introduction to the thematic series on the life and lifework of Mary Mandels, first lady of cellulase research. Biotechnol Biofuels. 2009;2:23.

7. Eveleigh DE, Montenecourt BS. Increasing yields of extracellular enzymes. Adv Appl Microbiol. 1979;25:57-74.

8. Peterson R, Nevalainen H. Trichoderma reesei RUT-C30-thirty years of strain improvement. Microbiology. 2012;158:58-68.

9. Torigoi E, Henrique-Silva F, Escobar-Vera J, Carle-Urioste JC, Crivellaro O, El-Dorry H, El-Gogary S. Mutants of Trichoderma reesei are defective in cellulose induction, but not basal expression of cellulase-encoding genes. Gene. 1996;173:199-203.

10. Nitta M, Furukawa T, Shida Y, Mori K, Kuhara S, Morikawa Y, Ogasawara W. A new Zn(II)(2)Cys(6)-type transcription factor BgIR regulates beta-glucosidase expression in Trichoderma reesei. Fungal Genet Biol. 2012:49:388-97.

11. Porciuncula Jde O, Furukawa T, Mori K, Shida Y, Hirakawa H, Tashiro K, Kuhara S, Nakagawa S, Morikawa Y, Ogasawara W. Single nucleotide polymorphism analysis of a Trichoderma reesei hyper-cellulolytic mutant developed in Japan. Biosci Biotechnol Biochem. 2013;77:534-43.

12. Ghassemi S, Lichius A, Bidard F, Lemoine S, Rossignol MN, Herold S, SeidlSeiboth V, Seiboth B, Espeso EA, Margeot A, Kubicek CP. The ss-importin KAP8 (Pse1/Kap121) is required for nuclear import of the cellulase transcriptional regulator XYR1, asexual sporulation and stress resistance in Trichoderma reesei. Mol Microbiol. 2015;96:405-18.

13. Hakkinen M, Valkonen MJ, Westerholm-Parvinen A, Aro N, Arvas M, Vitikainen M, Penttila M, Saloheimo M, Pakula TM. Screening of candidate regulators for cellulase and hemicellulase production in Trichoderma reesei and identification of a factor essential for cellulase production. Biotechnol Biofuels. 2014;7:14.

14. Le Crom S, Schackwitz W, Pennacchio L, Magnuson JK, Culley DE, Collett JR, Martin J, Druzhinina IS, Mathis H, Monot F, et al. Tracking the roots of cellulase hyperproduction by the fungus Trichoderma reesei using massively parallel DNA sequencing. Proc Natl Acad Sci USA. 2009:106:16151-6.

15. Shida Y, Yamaguchi K, Nitta M, Nakamura A, Takahashi M, Kidokoro S, Mori K, Tashiro K, Kuhara S, Matsuzawa T, et al. The impact of a singlenucleotide mutation of bgl2 on cellulase induction in a Trichoderma reesei mutant. Biotechnol Biofuels. 2015:8:230.

16. Vitikainen M, Arvas M, Pakula T, Oja M, Penttila M, Saloheimo M. Array comparative genomic hybridization analysis of Trichoderma reesei strains with enhanced cellulase production properties. BMC Genom. 2010;11:441.

17. Porciuncula Jde O, Furukawa T, Shida Y, Mori K, Kuhara S, Morikawa Y, Ogasawara W. Identification of major facilitator transporters involved in cellulase production during lactose culture of Trichoderma reesei PC-3-7. Biosci Biotechnol Biochem. 2013;77:1014-22.

18. Lichius A, Bidard F, Buchholz F, Le Crom S, Martin J, Schackwitz W, Austerlitz T, Grigoriev IV, Baker SE, Margeot A, et al. Genome sequencing of the Trichoderma reesei QM9136 mutant identifies a truncation of the transcriptional regulator XYR1 as the cause for its cellulase-negative phenotype. BMC Genom. 2015;16:326.

19. Druzhinina IS, Schmoll M, Seiboth B, Kubicek CP. Global carbon utilization profiles of wild-type, mutant, and transformant strains of Hypocrea jecorina. Appl Environ Microbiol. 2006;72:2126-33.

20. Schmoll M, Zeilinger S, Mach RL, Kubicek CP. Cloning of genes expressed early during cellulase induction in Hypocrea jecorina by a rapid subtraction hybridization approach. Fungal Genet Biol. 2004;41:877-87.

21. Schmoll M, Franchi L, Kubicek CP. Envoy, a PAS/LOV domain protein of Hypocrea jecorina (Anamorph Trichoderma reesei), modulates cellulase gene transcription in response to light. Eukaryot Cell. 2005;4:1998-2007.

22. Koike H, Aerts A, LaButti K, Grigoriev IV, Baker SE. Comparative genomics analysis of Trichoderma reesei strains. Ind Biotechnol. 2013:9:352-67.

23. Castellanos F, Schmoll M, Martinez P, Tisch D, Kubicek CP, Herrera-Estrella A, Esquivel-Naranjo EU. Crucial factors of the light perception machinery and their impact on growth and cellulase gene transcription in Trichoderma reesei. Fungal Genet Biol. 2010;47:468-76.

24. Marie-Nelly H, Marbouty M, Cournac A, Flot JF, Liti G, Parodi DP, Syan S, Guillen N, Margeot A, Zimmer C, Koszul R. High-quality genome (re) assembly using chromosomal contact data. Nat Commun. 2014;5:5695.

25. Druzhinina IS, Kopchinskiy AG, Kubicek EM, Kubicek CP. A complete annotation of the chromosomes of the cellulase producer Trichoderma reesel provides insights in gene clusters, their expression and reveals genes required for fitness. Biotechnol Biofuels. 2016;9:75.

26. Jourdier E, Baudry L, Poggi-Parodi D, Vicq Y, Koszul R, Margeot A, Marbouty M, Bidard F. Proximity ligation scaffolding and comparison of two Trichoderma reesei strains genomes. Biotechnol Biofuels. 2017;10:151.

27. Farkas V, Sestak S, Gresíak M, Kolarova N, Labudova L, Bauer S. Induction of cellulase in Trichoderma reesei grown on lactose. Acta Biotechnol. 1987:5:425-9.

28. Tsitsigiannis DI, Zarnowski R, Keller NP. The lipid body protein, PpoA, coordinates sexual and asexual sporulation in Aspergillus nidulans. J Biol Chem. 2004:279:11344-53.

29. Xiang Q, Glass NL. Identification of vib-1, a locus involved in vegetative incompatibility mediated by het-c in Neurospora crassa. Genetics. 2002;162:89-101.

30. Slattery MG, Liko D, Heideman W. The function and properties of the Azf1 transcriptional regulator change with growth conditions in Saccharomyces cerevisiae. Eukaryot Cell. 2006;5:313-20.

31. Tian C, Beeson WT, lavarone AT, Sun J, Marletta MA, Cate JH, Glass NL. Systems analysis of plant cell wall degradation by the model filamentous fungus Neurospora crassa. Proc Natl Acad Sci USA. 2009;106:22157-62.

32. Shahi S, Fokkens L, Houterman PM, Rep M. Suppressor of fusion, a Fusarium oxysporum homolog of Ndt80, is required for nutrient-dependent regulation of anastomosis. Fungal Genet Biol. 2016;95:49-57.

33. Li J, Wang J, Wang S, Xing M, Yu S, Liu G. Achieving efficient protein expression in Trichoderma reesei by using strong constitutive promoters. Microb Cell Fact. 2012:11:84

34. Paul S, Klutts JS, Moye-Rowley WS. Analysis of promoter function in Aspergillus fumigatus. Eukaryot Cell. 2012;11:1167-77.

35. Sibthorp C, Wu H, Cowley G, Wong PW, Palaima P, Morozov IY, Weedall GD, Caddick MX. Transcriptome analysis of the filamentous fungus Aspergillus nidulans directed to the global identification of promoters. BMC Genom. 2013;14:847.

36. Durand H, Clanet M, Tiraby G. Genetic improvement of Trichoderma reesei for large scale cellulase production. Enzym Microb Technol. 1988:10:341-6

37. Nevalainen KM, Palva ET. Production of extracellular enzymes in mutants isolated from Trichoderma viride unable to hydrolyze cellulose. Appl Environ Microbiol. 1978;35:11-6.

38. Cherry JR, Fidantsef AL. Directed evolution of industrial enzymes: an update. Curr Opin Biotechnol. 2003;14:438-43.

39. Xiong Y, Sun J, Glass NL. VIB1, a link between glucose signaling and carbon catabolite repression, is essential for plant cell wall degradation by Neurospora crassa. PLoS Genet. 2014;10:e1004500.

40. Cuozzo C, Porcellini A, Angrisano T, Morano A, Lee B, Di Pardo A, Messina S, luliano R, Fusco A, Santillo MR, et al. DNA damage, homology-directed repair, and DNA methylation. PLoS Genet. 2007:3:e110.

41. O'Hagan HM. Chromatin modifications during repair of environmental exposure-induced DNA damage: a potential mechanism for stable epigenetic alterations. Environ Mol Mutagen. 2014;55:278-91.

42. Ries L, Belshaw NJ, IImen M, Penttila ME, Alapuranen M, Archer DB. The role of CRE1 in nucleosome positioning within the cbh1 promoter and coding regions of Trichoderma reesei. Appl Microbiol Biotechnol. 2014:98:749-62.

43. Dementhon K, Iyer G, Glass NL. VIB-1 is required for expression of genes necessary for programmed cell death in Neurospora crassa. Eukaryot Cell. 2006;5:2161-73.

44. Katz ME, Braunberger K, Yi G, Cooper S, Nonhebel HM, Gondro C. A p53like transcription factor similar to $\mathrm{Ndt} 80$ controls the response to nutrient stress in the filamentous fungus, Aspergillus nidulans. F1000Res. 2013;2:72.

45. Niones JT, Takemoto D. VibA, a homologue of a transcription factor for fungal heterokaryon incompatibility, is involved in antifungal compound production in the plant-symbiotic fungus Epichloe festucae. Eukaryot Cell. 2015:14:13-24 
46. van Munster JM, Daly P, Delmas S, Pullan ST, Blythe MJ, Malla S, Kokolski M, Noltorp EC, Wennberg K, Fetherston R, et al. The role of carbon starvation in the induction of enzymes that degrade plant-derived carbohydrates in Aspergillus niger. Fungal Genet Biol. 2014;72:34-47.

47. Foreman PK, Brown D, Dankmeyer L, Dean R, Diener S, Dunn-Coleman NS, Goedegebuur F, Houfek TD, England GJ, Kelley AS, et al. Transcriptional regulation of biomass-degrading enzymes in the filamentous fungus Trichoderma reesei. J Biol Chem. 2003;278:31988-97.

48. Derntl C, Gudynaite-Savitch L, Calixte S, White T, Mach RL, Mach-Aigner AR. Mutation of the xylanase regulator 1 causes a glucose blind hydrolase expressing phenotype in industrially used Trichoderma strains. Biotechnol Biofuels. 2013;6:62.

49. Mach-Aigner AR, Pucher ME, Steiger MG, Bauer GE, Preis SJ, Mach RL. Transcriptional regulation of xyr1, encoding the main regulator of the xylanolytic and cellulolytic enzyme system in Hypocrea jecorina. Appl Environ Microbiol. 2008;74:6554-62.

50. Ivanova C, Baath JA, Seiboth B, Kubicek CP. Systems analysis of lactose metabolism in Trichoderma reesei identifies a lactose permease that is essential for cellulase induction. PLoS ONE. 2013;8:e62631.

51. Portnoy T, Margeot A, Linke R, Atanasova L, Fekete E, Sandor E, Hart L, Karaffa L, Druzhinina IS, Seiboth B, et al. The CRE1 carbon catabolite repressor of the fungus Trichoderma reesei: a master regulator of carbon assimilation. BMC Genom. 2011;12:269.

52. Li J, Lin L, Li H, Tian C, Ma Y. Transcriptional comparison of the filamentous fungus Neurospora crassa growing on three major monosaccharides D-glucose, D-xylose and L-arabinose. Biotechnol Biofuels. 2014;7:31.

53. Akel E, Metz B, Seiboth B, Kubicek CP. Molecular regulation of arabinan and $\mathrm{L}$-arabinose metabolism in Hypocrea jecorina (Trichoderma reesei). Eukaryot Cell. 2009;8:1837-44.

54. Stricker AR, Mach RL, de Graaff LH. Regulation of transcription of cellulases- and hemicellulases-encoding genes in Aspergillus niger and Hypocrea jecorina (Trichoderma reesei). Appl Microbiol Biotechnol. 2008;78:211-20.

55. Coradetti ST, Craig JP, Xiong Y, Shock T, Tian C, Glass NL. Conserved and essential transcription factors for cellulase gene expression in ascomycete fungi. Proc Natl Acad Sci USA. 2012;109:7397-402.

56. Znameroski EA, Glass NL. Using a model filamentous fungus to unravel mechanisms of lignocellulose deconstruction. Biotechnol Biofuels. 2013;6:6.

57. Bischof R, Fourtis L, Limbeck A, Gamauf C, Seiboth B, Kubicek CP. Comparative analysis of the Trichoderma reesei transcriptome during growth on the cellulase inducing substrates wheat straw and lactose. Biotechnol Biofuels. 2013;6:127.

58. Xiong Y, Wu VW, Lubbe A, Qin L, Deng S, Kennedy M, Bauer D, Singan VR, Barry K, Northen TR, et al. A fungal transcription factor essential for starch degradation affects integration of carbon and nitrogen metabolism. PLoS Genet. 2017;13:e1006737

59. Poggi-Parodi D, Bidard F, Pirayre A, Portnoy T, Blugeon C, Seiboth B, Kubicek CP, Le Crom S, Margeot A. Kinetic transcriptome analysis reveals an essentially intact induction system in a cellulase hyper-producer Trichoderma reesei strain. Biotechnol Biofuels. 2014;7:173.

60. Mandels M, Weber J, Parizek R. Enhanced cellulase production by a mutant of Trichoderma viride. Appl Microbiol. 1971;21:152-4.

61. Hartree EF. Determination of protein: a modification of the Lowry method that gives a linear photometric response. Anal Biochem. 1972;48:422-7.

62. Ghose TK. Measurement of cellulase activities. Pure Appl Chem. 1987;59:257-68.

63. Xiao Z, Storms R, Tsang A. Microplate-based filter paper assay to measure total cellulase activity. Biotechnol Bioeng. 2004;88:832-7.

64. Sternberg D, Mandels GR. Induction of cellulolytic enzymes in Trichoderma reesei by sophorose. J Bacteriol. 1979;139:761-9.

65. Hartl L, Kubicek CP, Seiboth B. Induction of the gal pathway and cellulase genes involves no transcriptional inducer function of the galactokinase in Hypocrea jecorina. J Biol Chem. 2007;282:18654-9.

66. Schiestl RH, Gietz RD. High efficiency transformation of intact yeast cells using single stranded nucleic acids as a carrier. Curr Genet. 1989;16:339-46.

67. Christianson TW, Sikorski RS, Dante M, Shero JH, Hieter P. Multifunctional yeast high-copy-number shuttle vectors. Gene. 1992;110:119-22.

68. Singh MV, Weil PA. A method for plasmid purification directly from yeast. Anal Biochem. 2002;307:13-7.

69. Penttila M, Nevalainen $H$, Ratto M, Salminen E, Knowles J. A versatile transformation system for the cellulolytic filamentous fungus Trichoderma reesei. Gene. 1987;61:155-64.

70. Metz B, Seidl-Seiboth V, Haarmann T, Kopchinskiy A, Lorenz P, Seiboth B, Kubicek CP. Expression of biomass-degrading enzymes is a major event during conidium development in Trichoderma reesei. Eukaryot Cell. 2011;10:1527-35

71. Jourdren L, Bernard M, Dillies MA, Le Crom S. Eoulsan: a cloud computing-based framework facilitating high throughput sequencing analyses. Bioinformatics. 2012;28:1542-3.

72. Langmead B, Trapnell C, Pop M, Salzberg SL. Ultrafast and memoryefficient alignment of short DNA sequences to the human genome. Genome Biol. 2009;10:R25.

73. Li H, Handsaker B, Wysoker A, Fennell T, Ruan J, Homer N, Marth G, Abecasis $G$, Durbin $R$. The sequence alignment/map format and SAMtools. Bioinformatics. 2009;25:2078-9.

74. Anders S, Huber W. Differential expression analysis for sequence count data. Genome Biol. 2010;11:R106.

75. Li W, Wooley JC, Godzik A. Probing metagenomics by rapid cluster analysis of very large datasets. PLoS ONE. 2008;3:e3375.

76. Chen K, Wallis JW, McLellan MD, Larson DE, Kalicki JM, Pohl CS, McGrath SD, Wendl MC, Zhang Q, Locke DP, et al. BreakDancer: an algorithm for high-resolution mapping of genomic structural variation. Nat Methods. 2009:6:677-81.

\section{Submit your next manuscript to BioMed Central and we will help you at every step:}

- We accept pre-submission inquiries

- Our selector tool helps you to find the most relevant journal

- We provide round the clock customer support

- Convenient online submission

- Thorough peer review

- Inclusion in PubMed and all major indexing services

- Maximum visibility for your research

Submit your manuscript at www.biomedcentral.com/submit
BioMed Central 